\title{
Preliminary Study on Drying of Stingless Bee Pot Pollen Using Novel Fluidized Bed Dryer with Swirling Distributor
}

\author{
Luqman Abdul Halim ${ }^{1}$, Firdaus Basrawi ${ }^{1, *}$, Jia Zheng Chong ${ }^{1}$, Ahmed Nurye Oumer ${ }^{1}$, \\ Ahmmad Shukrie Md Yudin ${ }^{1}$, Mohd Hazwan bin Yusof ${ }^{1}$, and Shaharin A Sulaiman ${ }^{2}$ \\ ${ }^{1}$ Meliponini Engineering Laboratory (MePEL), Energy Sustainability Focus Group (ESFG), Faculty \\ of Mechanical Engineering, Universiti Malaysia Pahang, 26600 Pekan, Pahang, Malaysia \\ ${ }^{2}$ Department of Mechanical Engineering, Universiti Teknologi PETRONAS, 32610 Seri Iskandar, \\ Malaysia
}

\begin{abstract}
High moisture content in raw pot pollen increases the activity of microorganisms, thus promotes fermentation and causes rapid deterioration. Hence, the objective of this study is to dry stingless bees pot pollen by a novel fluidized bed dryer. The experimental analysis was conducted based on flowrate, airflow temperature, power consumption and sample mass. It was found that the mass of pot pollen can be reduced by $6.86 \%$ in 30 minutes of drying operation. The temperature rise is also minimal up to average of $31.5^{\circ} \mathrm{C}$. This significantly reduced the impact of drying not only to the nutrients, but also the flavour and aroma. Moreover, the total energy consumed is $212.57 \mathrm{Wh}$, which is considered low. Hence, this preliminary study showed the feasibility of drying pot pollen using a novel fluidized bed dryer.
\end{abstract}

\section{Introduction}

Stingless bees species are native in tropical and subtropical region [1]. In Malaysia, stingless bees are called 'Kelulut' [2]. The popularity of their honey is making stingless bee farming or meliponiculture to gain traction especially in Malaysia as a source of income due to their honey price is higher than honey bees [3].

Currently, there are but a few studies on application of engineering in meliponiculture, such as for hive temperature regulation [1], [4], honey processing [5], [6] as well as engineering economic analysis for stingless bee keeping [7]. However, there is no study on engineering application for pollen collected by stingless bee.

Like stinging honey bees (Apis mellifera), stingless bees also collect and store pollen inside their nest. While pollen stored in Apis beehive is called beebread, pollen stored in meliponine (stingless bee) nest is called pot-pollen [8]. The term pot-pollen however is being used interchangeably with bee bread and bee pollen.

Pot-pollen is made up of pollen collected from flowers, mixed with nectar and bee secretion [9]. Dried and processed, they can be sold for higher price than honey [10]. Often

\footnotetext{
*Corresponding author: mfirdausb@ump.edu.my
} 
regarded as byproduct, pot-pollen are usually neglected by the farmers due to the lack of knowledge in harvesting and preservation method for pot-pollen. This is a wastage as they have high nutritive value as it contain high level of proteins, carbohydrates, lipids, vitamins and phenolic compounds [11]. Previous research on pot-pollen has shown that their extract contains antioxidant [12], besides having antibiotic and antimicrobial properties [12], [13]. They are even regarded as "complete food" as they contain all essential amino acid needed by humans [14].

Fresh pot-pollen have high moisture content. This can cause excessive fermentation and spoilage, deteriorating the quality of pot-pollen. Hence, preserving pot-pollen requires drying them with suitable techniques. However, conventional methods may lead to loss of nutrient and useful compounds. Table 1 below shows some of the conventional method for drying of bee bread.

Table 1: Disadvantages of conventional method for drying of bee bread [15].

\begin{tabular}{|c|c|}
\hline Method & Disadvantages \\
\hline $\begin{array}{c}\text { Sublimation drying at freezing } \\
\text { temperature in deep vacuum }\end{array}$ & Loss of bioactive compounds \\
\hline Conductive drying & Non-uniform drying \\
\hline Sun drying & Loss of bioactive compounds \\
\hline Infra-red drying & Caramelization and nutrient loss \\
\hline
\end{tabular}

Fluidized bed dryers (FBD) are being explored as an alternative to traditional and conventional methods such as sun drying, oven method, food dryers. The advantage of fluidized bed dryer is that it has higher heat and mass transfer rate. Application of FBD on food products are continuously being explored, as they can improve their shelf-life, reduce packaging costs, lower shipping weights, enhance appearance, to attempt to encapsulate original flavour and maintain nutritional value [16]. Some of the investigations on fluidized bed drying on food material are mostly on plant or vegetation based such as drying of kaffir lime leaves [17], drying of carrots [18], and banana slices [19]. However, little or no previous study on fluidized bed drying of pot-pollen has been done. The fluidized bed dryer could thus be a potential compact dryer for pot pollen drying [20]. Hence, this paper explores FBD as suitable alternative for pot pollen drying.

\section{Methodology}

The experiments were conducted at the Energy and Sustainability Focus Group laboratory, Faculty of Mechanical Engineering, Universiti Malaysia Pahang (UMP). Pot pollen sample used was sourced from a local stingless bee farm. The pot pollen sample was cleaned and stored at $-10{ }^{\circ} \mathrm{C}$ before experiment is carried out.

The schematics of the FBD used is shown in Fig. 1 below: 


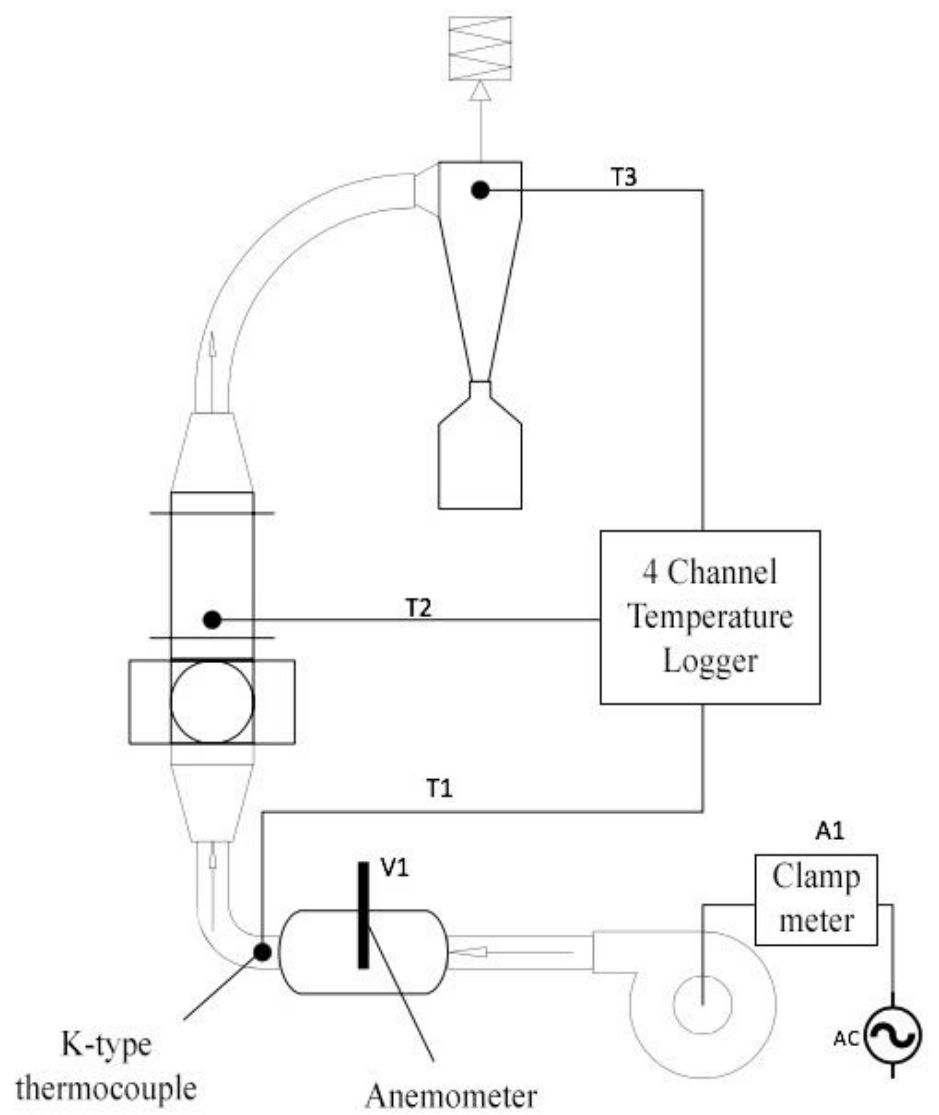

Fig. 1. Schematic of fluidized bed dryer for pot pollen drying, with sensors $\mathrm{T} 1:$ inlet temperature, $\mathrm{T} 2$ : Bed chamber temperature, T3 : Outlet temperature, V1 : Inlet air velocity, A1 : Electrical current

$350 \mathrm{~g}$ of pot pollen is dried in a fluidized bed dryer for 30 minutes at $2.0 \mathrm{~m}^{3} / \mathrm{min}$ air flowrates. The drying of pot pollen is quantified by measuring the mass loss during drying. The differences of mass before and after the experiment is expressed by Eq. (1) and the result indicates the mass loss of pot pollen.

$$
\Delta m=\sum m_{i}-\sum m_{f}
$$

where $\Delta \mathrm{m}$ is the mass difference [g], $\sum m_{i}$ is the total initial mass [g], and $\sum m_{f}$ is the total final mass $[\mathrm{g}]$.

The mass difference percentage is expressed in Eq. (2), using with the mass of pot pollen prior to drying.

$$
\Delta m \%=\frac{\Delta m}{m_{p p}} \times 100 \%
$$

where $\Delta \mathrm{m} \%$ is the mass difference percentage.

The average power, $\mathrm{P}[\mathrm{W}]$ is measured using a clamp meter. Then, the total power consumption, $\mathrm{E}[\mathrm{Wh}]$ is expressed as the product of $\mathrm{P}$ and total running time, $\mathrm{t}[\mathrm{h}]$

$$
\mathrm{E}=\mathrm{Pt}
$$

\section{Results and discussion}


Fig. 2. shows the temperature profile inside the fluidized bed chamber. In the beginning, there is a steady rise in temperature, before maintaining at average temperature of $31.5{ }^{\circ} \mathrm{C}$. This can be attributed to the heat produced from the blower. However, the increase is minimal and well within the natural stingless bee hive temperature [1]. Little or no heating is desirable in processing the pot pollen to maintain not only the nutrients, but also the flavours and aromas.

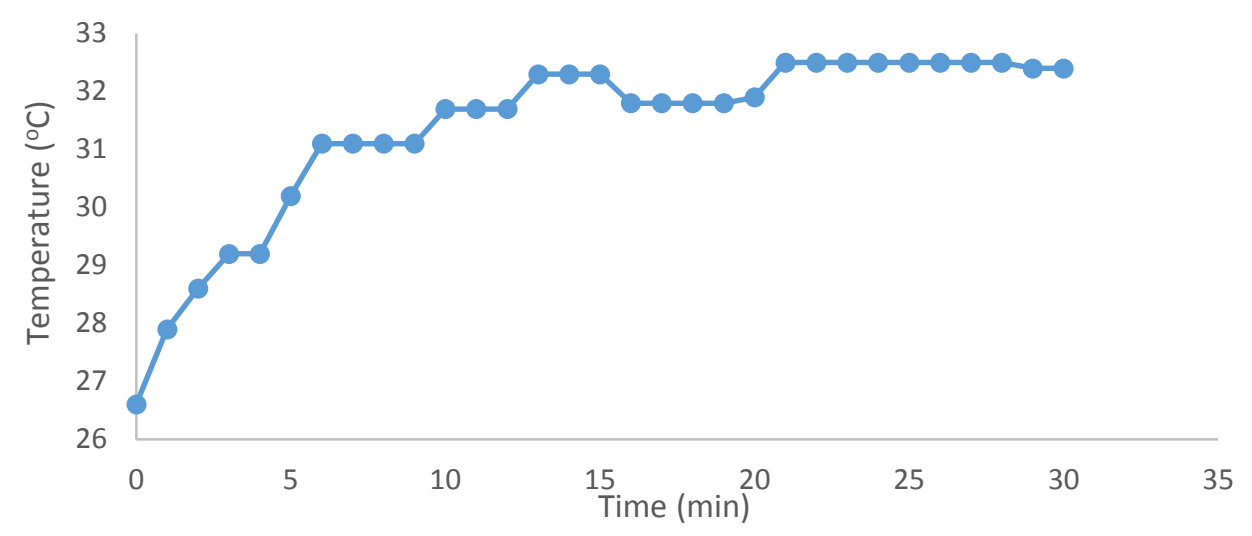

Fig. 2.: Temperature profile inside the fluidized bed chamber

The drying rate is represented by the percentage of mass reduction of the pot pollen throughout the experiment. The initial and final mass of the bed chamber and the separator were recorded and tabulated in Table 2.

Table 2: Flowrate, chamber temperature, mass reduction and total energy consumed for pot pollen drying

\begin{tabular}{ccccc}
\hline $\begin{array}{c}\text { Flowrate } \\
\left(\mathbf{m}^{3} / \mathbf{m i n}\right)\end{array}$ & $\begin{array}{c}\text { Average Bed Chamber } \\
\text { Temperature }\left({ }^{\circ} \mathbf{C}\right)\end{array}$ & $\begin{array}{c}\text { Mass } \\
\text { Difference } \\
(\mathbf{g})\end{array}$ & $\begin{array}{c}\text { Percentage of } \\
\text { Mass Reduction } \\
(\%)\end{array}$ & $\begin{array}{c}\text { Energy } \\
\text { Consumed } \\
(\mathbf{W h})\end{array}$ \\
\hline 2.0 & 31.51 & 24 & 6.86 & 212.57 \\
\hline
\end{tabular}

There is a $6.86 \%$ reduction in mass of the pot pollen at the end of the experiment. This indicates that moisture from the pot pollen has been dried in just 30 minutes. The total energy consumed is $212.57 \mathrm{Wh}$. At this low energy consumption, FBD drying of pot pollen showed promise as viable method to dry stingless bee pot pollen.

\section{Conclusion}

$350 \mathrm{~g}$ of stingless bee pot pollen sample is dried using fluidized bed dryer for 30 minutes at flowrate of $2.0 \mathrm{~m}^{3} / \mathrm{min}$. It was found that the drying cause reduction of mass of almost $7 \%$. This is very quick considering the average temperature is at $31.5^{\circ} \mathrm{C}$. This reduces the impact of elevated temperature towards the nutritional content of dried pot pollen. Besides, the energy consumption is minimal at $212.57 \mathrm{Wh}$. Hence, it is not only energy-saving but also economic. In conclusion, it is possible to dry pot pollen in a short duration at low temperature using the fluidized bed dryer.

The authors would like to thank Universiti Malaysia Pahang for providing assistance for this research through the access of Research Grant RDU1603111 


\section{References}

1. A. S. Ramli, A. H. Luqman, F. Basrawi, A. N. Oumer, A. A. Aziz, and Z. Mustafa, MATEC Web Conf., 131, 03013, 2017.

2. S. P. Kek, N. L. Chin, Y. A. Yusof, S. W. Tan, and L. S. Chua, Agric. Agric. Sci. Procedia, 2, 150-155, 2014.

3. M. Cortopassi-Laurino et al., Apidologie, 37, 275-292, Mar. 2006.

4. F. Basrawi, A. R. A Hamid, R. Bahari, M. N. Mohd Noordin, and M. H. Yusof, MATEC Web Conf., 131, 2-7, 2017.

5. A. S. Ramli et al., MATEC Web Conf., 131, 03014, 2017.

6. A. S. Ramli et al., Dry. Technol., 0, 1-7, 2018.

7. F. Basrawi, A. H. Ahmad, D. M. N. Daing Idris, M. R. M. Maarof, M. Chand, and A. S. Ramli, MATEC Web Conf., 131, 04005, 2017.

8. P. Vit, G. R. D'Albore, O. M. Barth, M. Peña-Vera, and E. Pérez-Pérez, in PotPollen in Stingless Bee Melittology, Cham: Springer International Publishing, 2018, 361-375.

9. R. M. de Oliveira Alves and C. A. L. Carvalho, in Pot-Pollen in Stingless Bee Melittology, Cham: Springer International Publishing, 2018, 435-443.

10. M. Kieliszek, K. Piwowarek, A. M. Kot, S. Błażejak, A. Chlebowska-Śmigiel, and I. Wolska, Trends Food Sci. Technol., 71, 170-180, 2018.

11. A. C. URCAN et al., Bull. Univ. Agric. Sci. Vet. Med. Cluj-Napoca. Anim. Sci. Biotechnol., 74, 6, May 2017.

12. R. A. M. Akhir, M. F. A. Bakar, and S. B. Sanusi, in AIP Conference Proceedings, 2017, 1891, 020090.

13. Z. Abouda, I. Zerdani, I. Kalalou, M. Faid, and M. T. Ahami, Research Journal of Microbiology, 6. 376-384, (2011).

14. X. Feas, M. P. Vazquez-Tato, L. Estevinho, J. A. Seijas, and A. Iglesias, Molecules, 17, 8359-8377, 2012.

15. R. Akhmetova, J. Sibgatullin, S. Garmonov, and L. Akhmetova, Procedia Eng., 42, 1822-1825, 2012.

16. R. Sivakumar, R. Saravanan, A. Elaya Perumal, and S. Iniyan, Renew. Sustain. Energy Rev., 61, 280-301, 2016.

17. S. M. Tasirin, I. Puspasari, A. W. Lun, P. V. Chai, and W. T. Lee, Ind. Crops Prod., 61, 193-201, 2014.

18. A. Reyes, P. I. Alvarez, and F. H. Marquardt, Dry. Technol., 20, 1463-1483, 2002.

19. W. P. da Silva, C. M. D. P. S. e Silva, F. J. A. Gama, and J. P. Gomes, J. Saudi Soc. Agric. Sci., 13, 67-74, 2014.

20. Y. Liu et al., Fuel Process. Technol., 122, 170-175, 2014. 